\title{
Assessment of sexual dysfunction in patients with inflammatory bowel disease
}

\author{
Dorota Szydlarska ${ }^{1}$, Alicja Jakubowska ${ }^{1}$, Grażyna Rydzewska ${ }^{1,2}$ \\ ${ }^{1}$ Department of Internal Medicine and Gastroenterology with IBD Subdivision, Central Clinical Hospital of the Ministry \\ of the Interior, Warsaw, Poland \\ ${ }^{2}$ Faculty of Health Sciences, Jan Kochanowski University, Kielce, Poland
}

Gastroenterology Rev 2019; 14 (2): 104-108

DOI: https://doi.org/10.5114/pg.2019.85893

Key words: sexual dysfunction, inflammatory bowel disease.

Address for correspondence: Dorota Szydlarska MD, Department of Internal Medicine and Gastroenterology with IBD Subdivision, Central Clinical Hospital of the Ministry of the Interior and Administration, 137 Woloska St, 02-507 Warsaw, Poland, phone: +48 601545915 , e-mail: dszydlarska@op.pl

\begin{abstract}
Inflammatory bowel disease (IBD) represents a diverse variety of chronic inflammatory intestinal conditions. Sexuality is often disturbed in patients with IBD, more often affecting women than men. Many factors seem to contribute to intimacy concerns. The most popular questionnaires used in empirical research around the world are the Female Sexual Function Index (FSFI) for women and the International Index of Erectile Function (IIEF) for men. Sexual satisfaction was negatively correlated with depression, anxiety, sexual problems, and illness perceptions. When analysing the problem of IBD, disorders of sexual function should not be ignored. Patients should be screened for psychological diseases and sexual dysfunction, and necessary treatments should be given as soon as possible. By understanding what factors contribute to poor sexual functioning in patients with IBD, we may try to minimise adverse psychosocial events. Screening for sexual disorders should be a part of daily medical practice.
\end{abstract}

\section{Introduction}

Inflammatory bowel disease (IBD) represents a diverse variety of chronic inflammatory intestinal conditions, with two major types: ulcerative colitis (UC) and Crohn's disease (CD). Inflammatory bowel disease is a complex disease, which arises as a result of the interactions of environmental and genetic factors leading to immunological responses and inflammation in the intestine [1]. Currently, the highest incidence of IBD is in Scandinavian countries, Great Britain, and North America; it is lower in Central Europe; and lowest in Asia and Africa. At the end of the last century, in the majority of countries, the rate of new cases was between 2 and 15 per 100,000 inhabitants, and the prevalence rate was 30-120 per 100,000 inhabitants. The incidence of UC has remained at a similar level throughout the years, whereas the incidence of IBD since the second half of the last century has been steadily increasing. IBD mainly affects people between 20 and 40 years of age. The second peak of disease is observed after the age of 60 years. The assessment of the incidence of
IBD in Poland, based on nationwide hospital records, showed that in 2007 there were 4.2 new cases of CD and 12.8 new cases of UC per 100,000 inhabitants. From 2004 to 2007, the number of new hospitalisations of patients with CD significantly increased, especially in the youngest age groups, and the number of hospitalisations due to UC decreased mainly in the elderly population. Inflammatory bowel disease diseases are becoming an increasingly common problem in clinical practice. Inflammatory bowel disease has multiple complications affecting patients' psychosocial life. Inflammatory bowel disease is likely to have an impact on sexual function because of the following symptoms: diarrhoea, fatigue, abdominal pain, rectal bleeding, and weight loss. Patients may suffer from anxiety, depression, and sexual dysfunction when the disease is active. When analysing the problem of IBD, disorders of sexual function should not be ignored. Patients should be screened for psychological diseases and sexual dysfunction, and necessary treatments should be given as soon as possible. 
The aim of this review was to assess the data regarding the impact of IBD on the sexual functioning of male and female patients.

Inflammatory bowel disease has been shown in many studies to negatively impact quality of life [2-4]. Relationships affected by sexual disorders alongside IBD seem to be a common problem $(20.6 \%)$ [2, 5]. As early as in 1978, the first reports showed decreased sexual activity among patients with IBD [6]. Epidemiological data show high prevalence of erectile dysfunction worldwide. The Massachusetts Male Aging Study (MMAS) showed that the overall prevalence of erectile dysfunction in the Boston area was $52 \%$ in men aged 40-70 years [7]. The detailed distribution of minimal, moderate, and severe erectile dysfunction was $17.2 \%$, $25.2 \%$, and $9.6 \%$, respectively. In Cologne, studies of men aged $30-80$ years showed a prevalence of erectile dysfunction at $19.2 \%$, with rapid increase related to age of $2.3 \%$ to $53.4 \%$ [8]. In a cross-sectional study among men seeking medical care because of erectile dysfunction, one in four men was under 40 years of age and almost 50\% had severe erectile dysfunction [9]. Erectile dysfunction has common, unmodifiable, and modifiable risk factors, including cardiovascular disease (e.g. obesity, diabetes, dyslipidaemia, metabolic syndrome, lack of exercise, and smoking) [10, 11].

Among sexual dysfunctions in women, there are distractions of desire, disturbances of arousal, orgasm disorders, and pain during sexual intercourse. Limitations resulting from a chronic disease affect almost every sphere of life. Inflammatory bowel disease most often affects young people who want to be professionally active, want to study, meet friends, and start a family. The disease often makes these goals difficult or even impossible. For a woman who wants to be attractive, the disease may have a negative impact on the patient's perception of her body. Using steroid therapy may result in high irritability, excess hair growth (women), red and ruddy face, red stretch marks, fatigue, acne, and irregular menstruation. Sexual function in IBD patients after surgery (ileostomy, proctocolectomy with ileal J-pouch-anal anastomosis, rectovaginal fistulae) may also be disturbed. A woman facing such an illness and its complications may lose self-confidence, become unhappy, and deny her true measures of attractiveness. Such a state may have an impact on social relationships, and, in more severe cases, it may have negative repercussions on the woman's psyche. Many women set a goal for motherhood which, for various reasons, must be postponed.

The most popular questionnaires used in empirical research around the world are the Female Sexual Function Index (FSFI) for women and the International
Index of Erectile Function (IIEF) for men. As informative as they are, they do not effectively address the unique symptoms and issues associated with sexual dysfunction in IBD patients. The IIEF-5 for males and the FSFI for females have been used in the majority of studies concerning IBD patients [12-18]. Most of these studies examined sexual function in both males and females. The sensitivity and specificity are adequate, but the IIEF seems to be limited by the exclusion of other aspects of male sexuality and the relationship with a partner [19]. The IIEF was originally developed in English and validated for the assessment of the degree of severity of erectile dysfunction. The survey is made up of 15 factors. The questionnaire comprises five categories: erectile function, orgasm, sexual desire, sexual satisfaction, and general satisfaction. The IIEF score ranges from 1 to 75 points. The erectile function category classifies the patients into five sub-categories: normal or without erectile dysfunction, mild erectile dysfunction, mild/moderate erectile dysfunction, moderate erectile dysfunction, and severe erectile dysfunction. In an effort to simplify the IIEF, a shortened five-factor version (IIEF-5, Table I) was developed to diagnose erectile dysfunction [20]. The newer, simplified version (consists of five questions) has proven to be a valid, specific, and sensitive scale for clinical use [21]. IIEF-5 is widely available on websites where the questionnaire can be completed by any interested person. The FSFI is a brief questionnaire to measure sexual function in women. It was developed for the specific purpose of assessing categories of sexual function in clinical trials. The FSFI consists of 19 items, and its aim is multifaceted evaluation of self-esteem in regard to sexual performance within the previous 4 weeks. This tool makes it possible to differentiate sexual dysfunctions in the area of desire, arousal, and achieving orgasm, as well as the feeling of sexual satisfaction. The presented tool is characterised by high credibility and is often used in research on women's sexuality around the world. Very diverse groups of women take part in these studies, for example patients with multiple sclerosis [22], hyperthyroidism [23], overweight [24], suffering from neoplastic diseases [25], or endometriosis [26]. In addition, the questionnaire is adaptable enough for use among women of varying stages of sexual development, from the pre- to post-menopausal periods [27].

\section{Other questionnaires \\ Female Sexual Distress Scale (FSDS)}

This questionnaire measures suffering associated with sexual dysfunction in women [28]. There is a Polish adaptation of the revised version: PL-FSDS-R [29]. 
Table I. The International Index of Erectile Function (IIEF-5) Questionnaire over past 6 months [20]

\begin{tabular}{|c|c|c|c|c|c|}
\hline Over the past 6 months & & & & & \\
\hline $\begin{array}{l}\text { 1. How do you rate your confidence that you } \\
\text { could get and keep an erection? }\end{array}$ & Very low 1 & Low 2 & Moderate 3 & High 4 & Very high 5 \\
\hline $\begin{array}{l}\text { 2. When you had erections with sexual } \\
\text { stimulation, how often were your erections } \\
\text { hard enough for penetration? }\end{array}$ & $\begin{array}{l}\text { Almost never/ } \\
\text { never } 1\end{array}$ & $\begin{array}{l}\text { A few times } \\
\text { (much less than } \\
\text { half the time) } 2\end{array}$ & $\begin{array}{l}\text { Sometimes } \\
\text { (about half the } \\
\text { time) } 3\end{array}$ & $\begin{array}{l}\text { Most times } \\
\text { (much more } \\
\text { than half the } \\
\quad \text { time) } 4\end{array}$ & $\begin{array}{l}\text { Almost always/ } \\
\text { always } 5\end{array}$ \\
\hline $\begin{array}{l}\text { 3. During sexual intercourse, how often were } \\
\text { you able to maintain your erection after } \\
\text { you had penetrated (entered) your partner? }\end{array}$ & $\begin{array}{l}\text { Almost never/ } \\
\text { never } 1\end{array}$ & $\begin{array}{l}\text { A few times } \\
\text { (much less than } \\
\text { half the time) } 2\end{array}$ & $\begin{array}{l}\text { Sometimes } \\
\text { (about half the } \\
\text { time) } 3\end{array}$ & $\begin{array}{l}\text { Most times } \\
\text { (much more } \\
\text { than half the } \\
\text { time) } 4\end{array}$ & $\begin{array}{l}\text { Almost always/ } \\
\text { always } 5\end{array}$ \\
\hline $\begin{array}{l}\text { 4. During sexual intercourse, how difficult } \\
\text { was it to maintain your erection to } \\
\text { completion of intercourse? }\end{array}$ & $\begin{array}{l}\text { Extremely } \\
\text { difficult } 1\end{array}$ & Very difficult 2 & Difficult 3 & $\begin{array}{l}\text { Slightly } \\
\text { difficult } 4\end{array}$ & Not difficult 5 \\
\hline $\begin{array}{l}\text { 5. When you attempted sexual intercourse, } \\
\text { how often was it satisfactory for you? }\end{array}$ & $\begin{array}{l}\text { Almost never/ } \\
\text { never } 1\end{array}$ & $\begin{array}{l}\text { A few times } \\
\text { (much less than } \\
\text { half the time) } 2\end{array}$ & $\begin{array}{l}\text { Sometimes } \\
\text { (about half the } \\
\text { time) } 3\end{array}$ & $\begin{array}{l}\text { Most times } \\
\text { (much more } \\
\text { than half the } \\
\quad \text { time) } 4\end{array}$ & $\begin{array}{l}\text { Almost always/ } \\
\text { always } 5\end{array}$ \\
\hline $\begin{array}{l}\text { IIEF-5 scoring: } \\
\text { The IIEF-5 score is the sum of the ordinal respo } \\
\text { 22-25: No erectile dysfunction } \\
\text { 17-21: Mild erectile dysfunction } \\
\text { 12-16: Mild to moderate erectile dysfunction } \\
\text { 8-11: Moderate erectile dysfunction } \\
\text { 5-7: Severe erectile dysfunction }\end{array}$ & ses to the 5 item & & & & \\
\hline
\end{tabular}

The tool contains 139 items covering topics such as sociodemographic data and broadly understood sexual behaviours, including the age of sexual initiation, the total number of sexual partners, permanent relationship status, sexual activity in recent times, sexual orientation, frequency of sexual intercourse, frequency of masturbation, quality of relationship with current partner, and history of sexual harassment.

\section{Arizona Sexual Experiences Scale (ASEX)}

This scale covers five factors that define the vigour of sex drive, excitement, penile erection/lubrication, the ability to achieve orgasm, and satisfaction associated with the experience of orgasm. Achieving a high score on the scale indicates the occurrence of sexual dysfunction [30].

\section{Sexual Dysfunction Questionnaire (SDQ)}

This scale helps determine the occurrence and severity of sexual dysfunction in people suffering from mental disorders. The questionnaire consists of 19 items and is intended for both men and women. The questionnaire primarily provides information on the presence of sexual dysfunction in the patient, in contrast to other questionnaires that reveal specific sexual dysfunctions [31].

\section{Discussion}

Bel et al. evaluated 168 female and 119 male IBD patients [32]. Patients were asked about depression, disease activity, IBD-related quality of life, body image, and fatigue. Patients with active disease scored significantly lower (IIEF-5 and FSFI) than patients in remission and controls, indicating impaired sexual functioning during disease activity. Significant associations were found between active disease, fatigue, depressive mood, quality of life, and sexual function, for both male and female patients. The association between disease activity and sexual function was totally mediated by depression. The researchers concluded that depression is the most important determinant for impaired sexual function in IBD. Other quality-of-life measures such as the McMaster Inflammatory Bowel Disease Questionnaire also have incorporated questions on sexual activity or satisfaction, acknowledging the interference of this factor with physical and psychosocial wellbeing [2]. Despite the obvious relevance to those inflicted, sexual problems are rarely addressed in the clinical care of IBD patients [33-35]. Timmer et al. showed that depressed mood was found to be the most important factor associated with decreased sexual function, irrespective of sex and the presence of IBD. In men with IBD in remission or mild activity, sexual function as measured 
by IIEF was not impaired as compared with controls. In women, there was some evidence of IBD-related impairment independent of disease activity. Activity of disease, depression, and sociologic factors all seem to play important roles in sexual dysfunction in patients with IBD [12]. Sexual function was better with longer disease duration and was not affected by the long-term severity of the disease [13]. Feelings of attractiveness and femininity, as well as satisfaction with bodily appearance, were impaired among females with active disease [36]. Depression was a predictor for low sexual function scores in IIEF [13]. The presence of diabetes was associated with lower scores in IIEF in the following categories: erectile function, orgasmic function, and sexual desire. Factors most predictive of low sexual function among females were depression, frequent relapses, anxiety, and current use of steroids. Marin et al. evaluated the prevalence and predisposing factors of sexual dysfunction among IBD patients from their own observations [36]. They reported significantly lower FSFI scores for female patients with IBD than with controls. Female patients, compared with males, had decreased libido and said their sexual satisfaction declined after IBD diagnosis [11]. Both men and women with IBD showed significantly lower scores in sexual function questionnaires as compared to controls. Independent predictors of sexual dysfunction among IBD patients were corticosteroids used by women, the use of biological agents, depression, and diabetes in men. Patients reported frequent problems with their body image, often influenced by surgical scars, and thinness. The study showed that sexuality is often disturbed in IBD patients, particularly among women. Many factors seem to contribute to worsened intimacy. Sexuality should be considered when quality of life $(\mathrm{QoL})$ is assessed in these patients. Muller et al. also attempted to explore the patients' perspectives regarding the impact of IBD on sexuality [37]. In their study, 347 patients were surveyed about relationships, QoL, body image, and sexual function. Women reported significantly decreased frequency of sexual activity (female $66.3 \%$ vs. male $40.5 \%$ ). Women were more likely to report decreased libido (female $67.1 \%$ vs. male $41.9 \%$ ). Fewer than $10 \%$ declined medication due to perceived negative side effects impacting sexual function. Poor perception of the female body image was common. The majority of the studies showed impaired sexual function among IBD patients, with female patients more adversely affected than males [14, 38, 39]. Knowles et al. aimed to characterise the relationships between illness perceptions, body image and self-consciousness, sexual health (sexual problems and sexual satisfaction), anxiety and depression, and marital and family functioning in patients with IBD [39]. The find- ings provided evidence of the adverse impact of patient IBD-related illness perceptions on anxiety and depression and psychological comorbidity in relation to sexual health as well as relationship difficulties and family function. Surgery did not influence the results. Sexual satisfaction was negatively correlated with depression, anxiety, sexual problems, and illness perceptions. Moreover, sexual problems, body image, and self-consciousness during intimacy correlated strongly with illness perception, anxiety, and depression.

\section{Conclusions}

Sexuality is often disturbed in patients with IBD. Many factors seem to contribute to a lack of interest in intimacy. Sexuality should be considered when QoL is assessed in these patients. By understanding what factors contribute to poor sexual function in patients with IBD, we may try to minimise adverse psychosocial events. Screening for sexual disorders should be a part of daily medical practice.

\section{Conflict of interest}

The authors declare no conflict of interest.

\section{References}

1. Szydlarska D, Jakubowska A, Moniuszko A, et al. Zakażenie Clostridium difficile u pacjentów z nieswoistymi zapalnymi chorobami jelit. Terapia 2016; 10: 38-43.

2. Bokemeyer B, Hardt J, Hüppe D, et al. Clinical status, psychosocial impairments, medical treatment and health care costs for patients with inflammatory bowel disease (IBD) in Germany: an online IBD registry. J Crohn Colitis 2013; 7: 355-68.

3. Iglesias-Rey M, Barreiro-de Acosta M, Caamaño-Isorna F, et al. Psychological factors are associated with changes in the health-related quality of life in inflammatory bowel disease. Inflamm Bowel Dis 2014; 20: 92-102.

4. Naliboff BD, Kim SE, Bolus R, et al. Gastrointestinal and psychological mediators of health-related quality of life in IBS and IBD: a structural equation modeling analysis. Am J Gastroenterol 2012; 107: 451-9.

5. Lönnfors S, Vermeire S, Greco M, et al. IBD and health-related quality of life - discovering the true impact. J Crohns Colitis 2014; 8: 1281-6.

6. Gazzard BG, Price HL, Libby GW, et al. The social toll of Crohn's disease. Br Med J 1978; 2: 1117-9.

7. Feldman S. Managed mental health-community mental health revisited? Manag Care Q 1994; 2: 13-8.

8. Braun M, Wassmer G, Klotz T, et al. Epidemiology of erectile dysfunction: results of the 'Cologne Male Survay. Int J Impot Res 2000; 12: 305-11.

9. Capogrosso P, Colicchia M, Ventimiglia E, et al. One patient out of four with newly diagnosed erectile dysfunction is a young man-worrisome picture from the everyday clinical practice. J Sex Med 2013; 10: 1833-41. 
10. Althof SE, Buvat J, Gutkin SW, et al. Sexual satisfaction in men with erectile dysfunction: correlates and potential predictors. J Sex Med 2010; 7: 203-15.

11. Salonia A, Castagna $G$, Saccà $A$, et al. Is erectile dysfunction a reliable proxy of general male health status? The case for the International Index of Erectile Function-Erectile Function domain. J Sex Med 2012; 9: 2708-15.

12. Timmer A, Bauer A, Dignass A, et al. Sexual function in persons with inflammatory bowel disease: a survey with matched controls. Clin Gastroenterol Hepatol 2007; 5: 87-94.

13. Timmer A, Bauer A, Kemptner D, et al. Determinants of male sexual function in inflammatory bowel disease: a survey-based cross-sectional analysis in 280 men. Inflamm Bowel Dis 2007; 13: 1236-43.

14. Bengtsson J, Lindholm E, Nordgren S, et al. Sexual function after failed ileal pouch-anal anastomosis. J Crohns Colitis 2011; 5: 407-14.

15. Ogilvie JW, Jr Goetz L, Baxter NN, et al. Female sexual dysfunction after ileal pouch-anal anastomosis. Br J Surg 2008 . 95: 887-92.

16. Wang JY, Hart SL, Wilkowski KS, et al. Gender-specific differences in pelvic organ function after proctectomy for inflammatory bowel disease. Dis Colon Rectum 2011; 54: 66-76.

17. Cornish J, Wooding K, Tan E, et al. Study of sexual, urinary, and fecal function in females following restorative proctocolectomy. Inflamm Bowel Dis 2012; 18: 1601-7.

18. Riss S, Schwameis K, Mittlböck $M$, et al. Sexual function and quality of life after surgical treatment for anal fistulas in Crohn's disease. Tech Coloproctol 2013; 17: 89-94.

19. Rosen RC, Cappelleri JC, Gendrano N. 3rd The International Index of Erectile Function (IIEF): a state-of-the-science review. Int J Impot Res 2002; 14: 226-44.

20. Rosen RC, Cappelleri JC, Smith MD, et al. Development and evaluation of an abridged, 5-item version of the International Index of Erectile Function (IIEF-5) as a diagnostic tool for erectile dysfunction. Int J Impot Res 1999; 11: 319-26.

21. Cappelleri JC, Rosen RC. Reply to 'The sexual health inventory for men (IIEF-5)' by Ja Vroege. Int J Impot Res 1999; 11: 353-4.

22. Solmaz V, Ozlece HK, Him A, et al. Evaluation of the association between sexual dysfunction and demyelinating plaque location and number in female multiple sclerosis patients. Neuro Res 2018; 40: 683-8.

23. Atis G, Dalkilinc A, Altuntas Y, et al. Hyperthyroidism: a risk fac tor for female sexual dysfunction. J Sex Med 2011; 8: 2327-33.

24. Jamali S, Zarei H, Rasekh Jahromi A. The relationship between body mass index and sexualfunction in infertile women a cross-sectional survey. Iran J Reprod Med 2014; 12: 189-98.

25. Baser RE, Li Y, Carter J. Psychometric validation of the Female Sexual Function Index (FSFI) in cancer survivors. Cancer 2012 118: 4606-18.

26. Evangelista A, Dantas T, Zendron C, et al. Sexual function in patients with deep infiltrating endometriosis. J Sex Med 2014, 11: 140-5.

27. Revicki DA, Margolis MK, Bush EN, et al. Content validity of the Female Sexual Function Index (FSFI) in pre- and postmenopausal women with hypoactive sexual desire disorder. J Sex Med 2011; 8: 2237-45.
28. DeRogatis LR, Rosen R, Leiblum S, et al. The Female Sexual Distress Scale (FSDS): Initial validation of a standardized scale for assessment of sexually related personal distress in women. J Sex Marital Ther 2002; 28: 317-30.

29. Nowosielski K, Wróbel B, Sioma-Markowska U, et al. Sexual dysfunction and distress-development of a Polish version of the female sexual distress scale-revised. J Sex Med 2013; 10: 1304-12.

30. McGahuey CA Gelenberg AJ, Laukes CA, et al. The Arizona Sexual Experience Scale (ASEX): reliability and validity. J Sex Marital Ther 2000; 26: 25-40.

31. Infrasca R. Sexual Dysfunction Questionnaire: scale development and psychometric Validation J Psychopathol 2011; 17: 253-60.

32. Bel LG, Vollebregt AM, Van der Meulen-de Jong, et al. Sexual dysfunctions in men and women with inflammatory bowel disease: the influence of ibd-related clinical factors and depression on sexual function. J Sex Med 2015; 12: 1557-67.

33. de Rooy EC, Toner BB, Maunder RG, et al. Concerns of patients with inflammatory bowel disease: results from a clinical population. Am J Gastroenterol 2001; 96: 1816-21.

34. Dubinsky CM. Sexuality issues in IBD. Pract Gastroenterol 2005; 24: 55-65.

35. Trachter AB, Rogers, Al, Leiblum SR. Inflammatory bowel disease in women: impact on relationship and sexual health. Inflamm Bowel Dis 2002; 8: 413-21.

36. Marin L, Manosa M, Garcia-Planella E, et al. Sexual function and patients' perceptions in inflammatory bowel disease: a case-control survey. J Gastroenterol 2013; 48: 713-20.

37. Muller KR, Prosser R, Bampton P, et al. Female gender and surgery impair relationships, body image, and sexuality in inflammatory bowel disease: patient perceptions. Inflamm Bowel Dis 2010; 16: 657-63.

38. Timmer A, Kemptner D, Bauer A, et al. Determinants of female sexual function in inflammatory bowel disease: a survey based cross-sectional analysis. BMC Gastroenterol 2008; 8: 45.

39. Knowles SR, Gass C, Macrae F. Illness perceptions in IBD influence psychological status, sexual health and satisfaction, body image and relational functioning: a preliminary exploration using Structural Equation Modeling. J Crohns Colitis 2013; 7: 344-50.

Received: 8.02.2019

Accepted: 8.03.2019 